\title{
Mulheres na universidade: a presença feminina no movimento estudantil paranaense (1964-85)
}

\author{
Women at the university: the female presence in the \\ student movement in Paraná State (1964-85)
}

Mujeres en la universidad: la presencia femenina en el movimiento estudiantil del Paraná (1964-85)

LUANA REGINA BORGES (iDa

ALEXANDRE FeLIPE FIUZA (iD $\mathrm{b}$

\section{Resumo}

Este texto aborda a participação feminina no movimento estudantil (ME) universitário paranaense durante a ditadura civil-militar brasileira (1964-1985), tendo como foco de análise preliminar o processo histórico da inserção feminina na educação formal e no ensino superior ao longo dos séculos XIX e XX. Para tal artigo, valeu-se da historiografia sobre o tema, dos estudos feministas de Joana Maria Pedro (2005) e Ana Maria Colling (1997, 2004). Para a análise do caso paranaense, adotou-se como fonte de análise a documentação presente no arquivo da Delegacia de Ordem Política e Social (DOPS), do Estado do Paraná, bem como de entrevistas publicadas com mulheres militantes, vítimas da violência estatal. A partir do exame das fontes, da historiografia e dos depoimentos das militantes, construiu-se uma breve história da inserção feminina no interior do movimento estudantil paranaense. A partir deste estudo, observou-se como a luta política das mulheres no interior do ME universitário paranaense se solidificou e ganhou amplitude, em plena ditadura, guardando similaridades com a luta empreendida pelas mulheres ao longo do século $\mathrm{XX}$, bem como sendo caudatária da organização da classe estudantil e da luta feminista no Brasil. Com o fim do período autoritário e durante a transição, estas mulheres

\footnotetext{
a Universidade Estadual do Oeste do Paraná (UNIOESTE), Cascavel, PR, Brasil. Mestra em Educação, e-mail: borgesluana91@gmail.com

b Universidade Estadual do Oeste do Paraná (UNIOESTE), Cascavel, PR, Brasil. Doutor em História, e-mail: alefiuza1970@gmail.com
} 
ocuparam espaços de liderança nos mais diferentes campos da luta social e da representação política, organizativa e sindical.

Palavras-chave: Mulheres. Movimento estudantil. Paraná. Ditadura. Universidade.

\begin{abstract}
This paper approaches the female participation in the university student movement (SM) in Paraná State during the Brazilian civil-military dictatorship system (1964-1985), having as the main focus of the preliminary analysis the historical process of the female insertion in the formal education and in high school along the nineteenth and twentieth century. In order to that, this paper relies on the historiography theme of the feminist studies of Joana Maria Pedro (2005) and Ana Maria Colling (1997, 2004). For the analysis of the Paraná State case, we adopted as an analysis source the documentation present in the archives of the Police Station of Political and Social Order (PSPSO), from Paraná State, and the interviews published with the militant women, victims of the state violence. From the examination of the sources, historiography and militant testimony, we built a brief history of the female insertion inside the student movement in Paraná State. From this study on, we observed how the political struggle of the women inside the university student movement in Paraná State solidified itself and gained amplitude, during the time of the dictatorship system, having similarities with the cause undertaken by women along the twentieth century, as well as being a follower of the organization of the student group and of the feminist struggle in Brazil. With the end of the authoritarian period and during its transition, these women occupied leadership positions in the most different fields of social struggle and of trade union, organizational and political representation.
\end{abstract}

Keywords: Women. Student movement. Paraná. Dictatorship. University.

\title{
Resumen
}

Este texto analiza la participación femenina en el movimiento estudiantil (ME) en la universidad del Paraná durante la dictadura civil-militar brasileña (1964-1985), centrándose en el análisis preliminar en el proceso histórico de inserción femenina en la educación formal y en la educación superior a lo largo de los siglos XIX y XX. Para este artículo, se utilizó la historiografía sobre el tema, los estudios feministas de Joana Maria Pedro (2005) y Ana Maria Colling (1997, 2004). Para el análisis del caso del Paraná, se adoptó como fuente de análisis la documentación presente en el archivo de la Policía del Orden Social y Político (DOPS), del Estado de Paraná, así como las entrevistas publicadas con mujeres militantes, víctimas de violencia estatal. A partir del examen de las fuentes, la historiografía y los testimonios de las militantes, se construyó una breve historia de la inserción femenina dentro del movimiento estudiantil del Paraná. A partir de este estudio, se observó cómo la lucha política de las mujeres en el interior del ME universitario del Paraná se solidificó y ganó amplitud, en medio a la dictadura, manteniendo similitudes con la lucha emprendida por las mujeres a lo largo del siglo XX, además de ser resultado 
de la organización de la clase estudiantil y de la lucha feminista en Brasil. Con el final del período autoritario y durante la transición, estas mujeres ocuparon espacios de liderazgo en los campos más diferentes de la lucha social y de la representación política, organizativa y sindical.

Palabras clave: Mujeres. Movimiento estudiantil. Paraná. Dictadura. Universidad.

\section{Introdução}

Com o fim da ditadura civil-militar brasileira (1964-1985), uma profícua produção historiográfica dedicou sua atenção a diversos elementos e processos históricos presentes no período autoritário. Apesar desta gama de estudos, a mulher foi inserida no interior de um conceito mais abrangente, ao menos nesta instância, de classe social ou dos grupos e movimentos sociais. Por conseguinte, a categoria de gênero acabou por ser subsumida por uma visão de mais amplo espectro numa significativa parte desta historiografia. Todavia, a história, como mestra da vida que é, ganha pulsão e potência justamente nas perguntas que emergem da contemporaneidade e da cotidianidade. Assim, nas duas últimas décadas, com a permanência e, em alguns casos, com o aumento ou maior visibilidade da violência de gênero, uma série de estudos das mais diferentes áreas das ciências humanas e sociais voltou seu foco à particularidade da experiência feminina nas tramas sociais e históricas.

Partindo desta premissa, este artigo almeja contribuir para uma análise da participação feminina no movimento estudantil (ME) universitário paranaense, uma vez que a maioria dos estudos se pauta na experiência dos dois Estados mais expressivos no campo da luta estudantil, São Paulo e Rio de Janeiro. Não obstante, ainda que estas experiências sejam representativas do que aconteceu em outros estados, inclusive por abranger a organização do ME a nível nacional, destaca-se aqui a particularidade do caso paranaense. Em parte, o protagonismo dessas mulheres foi pouco destacado pela história, pois a grande violência e repressão vivenciadas à época inibiram o desvelamento de muitas histórias, principalmente as que atingiam as mulheres ${ }^{1}$.

\footnotetext{
${ }^{1} \mathrm{Na}$ última década, como afirmado, muitos/as pesquisadores/as, principalmente adeptos da história oral, permitiram que a sociedade viesse a conhecer muitas destas histórias femininas 
Assim sendo, buscamos aqui identificar a participação e a atuação dessas mulheres no movimento estudantil paranaense durante o período ditatorial (19641985), tendo como fonte de análise os documentos que foram produzidos e apreendidos pela Delegacia de Ordem Política e Social (DOPS) do Estado do Paraná no referido período. A partir do levantamento minucioso e do exame detido das fontes documentais disponíveis no Arquivo Público do Paraná, ligadas ao aparato repressivo da ditadura, bem como realizando uma revisão bibliográfica da literatura pertinente, busca-se aqui identificar a militância feminina estudantil à época.

Tendo em vista tais preocupações e perspectivas para organizar a análise e a exposição do extenso material coletado, optamos por separar seu estudo de acordo com a natureza das Pastas presentes no arquivo da DOPS, sendo que primeiramente foram revisadas as Pastas Temáticas do movimento estudantil, tanto nacional quanto estadual, e em seguida as Pastas Individuais de mulheres estudantes que militaram no período de 1964 a 1985. Estes documentos oriundos do acervo da polícia política, como apontam Braggio e Fiuza (2013), são novas fontes para o trabalho com a história da educação, pois significativa parte do material produzido pelo e sobre o movimento estudantil não se encontra mais presente nas organizações estudantis. Afinal, ser portador de tais materiais durante a ditadura se traduzia num risco de sofrer a violenta repressão estatal de então.

A presença das mulheres no ensino superior a partir da década de 1960 permitiu que elas experimentassem a militância nas universidades por meio do movimento estudantil, bem como por meio de sua inserção em outros movimentos. Esta militância passa a ser significativa não apenas para a luta pela redemocratização do país, mas também pela emancipação feminina.

Desta maneira, respalda-se esta discussão sobre a militância feminina a partir dos estudos de Joana Maria Pedro (2005) e Ana Maria Colling (2004), que abordam a militância das mulheres no contexto da ditadura militar, bem como no estudo de

que ficaram escondidas após o período de redemocratização. São trabalhos de várias áreas do conhecimento, mas que destacam estes protagonismos. No Paraná podemos citar alguns, como "Sem liberdade eu não vivo" de Suelen Lorianny e Laura Beal Bordin (2013) e "Memórias do sótão: Vozes de mulheres na militância política contra a ditadura no Paraná (1964-1985)" de Carla C. N. Conradi (2015), além do Relatório da Comissão Estadual da Verdade do Paraná Teresa Urban (2017) e do projeto "Depoimentos para a história: A resistência à ditadura militar no Paraná" de Antônio Narciso Pires de Oliveira, Fábio Bacila Sahd e Silvia Calciolari (2014). 
Roberta Sousa e Teresa Bezerra (2006), que abordam a temática da militância feminina no movimento estudantil no mesmo período.

\section{Uma formação para a militância}

O ingresso das mulheres nas universidades a partir de 1960 levou muitas delas a questionar a sociedade e a almejar uma participação mais efetiva no campo político. De acordo com Wolff (2010, p. 146), “[...] cursos como Ciências Sociais, História, Filosofia, Letras e Psicologia eram aceitos como viáveis para as mulheres² e, por outro lado, pelo cunho político de sua discussão disciplinar, eram muitas vezes focos de recrutamento para o movimento estudantil". Por conseguinte, a presença feminina nos bancos universitários propiciou, por extensão, a formação da militante estudantil.

No interior das universidades, as estudantes tiveram maior contato com teorias políticas e econômicas, foram levadas a conhecer e questionar os valores impostos pela sociedade, adentraram ao palco de debates e contestações dos discursos produzidos pelos representantes políticos. Além do mais, o ingresso no ensino superior oportunizou novas possibilidades de projetos pessoais e profissionais, o que não era vislumbrado pelas suas gerações passadas (GIANORDOLI-NASCIMENTO et al., 2015). De fato, este cenário dentro da universidade contribuiu para uma formação das estudantes na militância.

O movimento estudantil neste estudo se inscreve num campo de investigação que integra o campo educacional ao político. Expressão desta confluência é a atuação do ME na representação dos interesses da juventude, mobilizando estudantes na defesa da educação, inclusive em projetos de alfabetização, cujo método pautava-se em Paulo Freire, em projetos culturais, na defesa da classe trabalhadora e na conscientização do povo.

\footnotetext{
${ }^{2}$ De acordo com dados do MEC de 1956, coletados por Barroso e Mello (1975), dos 10.555 estudantes das áreas de Letras, Ciências Humanas (Geografia, Pedagogia, Psicologia, História) e Filosofia, 67\% eram mulheres. Já das 1.592 matrículas em Enfermagem, 99\% correspondiam às mulheres. Enquanto isso, as alunas em outras áreas ocupavam 12\% das 20.607 cadeiras universitárias do curso de Direito e totalizavam 2\% das 8.223 matrículas em Engenharia.
} 
Com o ingresso das mulheres nas universidades, o ME passou a recrutá-las. Porém, esta presença feminina deve ser vista para além das novas calouras nos campos universitários. As estudantes que passaram a militar assim o fizeram por se identificar com as lutas e bandeiras que o movimento levantava. Essa agremiação permitiu que muitas estudantes viessem a romper com o padrão de feminino, no qual o destino das moças era marcado pelo casamento-maternidade. Para Santos (2011, p. 38) “os novos sujeitos políticos, constituídos a partir desta inserção nos movimentos sociais, têm em sua formação uma trajetória do privado para o público”.

O estudo sobre a integração feminina a um movimento de caráter político-educacional nos anos de efetiva restrição da liberdade caracteriza-se como essencial para compreender que a entrada da mulher na universidade foi um decisivo meio de ocupação do espaço público. Como indicam Barroso e Mello (1975), na metade dos anos 1950 a presença feminina no ensino superior correspondia a apenas 26\% das matrículas, aumentando para 40\% do total de matrículas em 1971. Portanto, de acordo com as entrevistas realizadas pela historiadora Ana Maria Colling (1997) em seu livro A resistência da mulher à ditadura militar no Brasil, adentrar no movimento estudantil permitiu que muitas estudantes concretizassem naquele ambiente as suas convicções políticas.

Não obstante, historicamente, a entrada das mulheres em movimentos políticos aconteceu de duas formas: ou subordinando-se ao padrão dominante já instituído naquele grupo ou rompendo com os padrões impostos para o seu gênero (SOUSA; BEZERRA, 2006). Ao adentrar no movimento estudantil, as estudantes assumiram uma militância de acordo com a organização masculinizada do movimento.

O movimento estudantil identificava os militares no poder como resultado inicial do projeto político das elites, enquanto os estudantes buscavam defender os direitos educacionais para a classe popular trabalhadora (SANFELICE, 1986). Assim, os estudantes atuavam no cenário político-educacional a partir de um viés de luta de classes. Todavia, neste sentido, o ME ainda não cedia espaço para o debate sobre as questões femininas e a condição da mulher na sociedade. As aspirações do ME pós-golpe militar eram relacionadas à luta pela democracia, defesa da universidade e contra o aparato repressivo da ditadura civil-militar. 
De acordo com Colling (2004), a ditadura militar no Brasil caracterizou os sujeitos como antagônicos, dividindo-os entre posição e oposição, como já esboçado por outros regimes autoritários na história. Desta maneira, essa dicotomia marcou os movimentos de esquerda, que identificavam os sujeitos entre proletariado e burguesia. Nesta dinâmica, priorizava-se o debate sobre a luta de classes, não oportunizando as demais questões, como era o caso da questão de gênero.

É importante ressaltar que as mulheres cuja participação se dava neste movimento político-educacional na década de 1960 e 1970 tinham como prioridade os ensejos do movimento estudantil, a luta de classes e a derrubada do regime. Assim, até então, estes espaços não seriam vistos essencialmente como oportunos para a discussão sobre a condição da mulher e o seu papel dentro do movimento político pela própria categoria.

Contudo, ao compor a militância do ME essas estudantes integraram-se em um campo político-educacional, meio este predominantemente masculinizado pela sociedade. Desta maneira, nos anos de forte repressão, mesmo sem haver espaço para as discussões dos temas femininos dentro do ME, havia por parte das militantes o rompimento com o modelo masculino imposto e o estreitamento com a vivência política, até então restringida a elas. Nesse contexto, as universitárias "rompem com os padrões estabelecidos, ousando entrar na arena política, espaço masculino por excelência" (COLLING, 1997, p. 22).

A partir do levantamento e análises das fontes podemos identificar dois momentos na militância feminina no movimento estudantil em apreço. O primeiro deles está localizado entre 1964, ano do golpe e início destas análises, até o início dos anos 1970. O segundo período data de 1980, quando se tem o retorno da União Paranaense de Estudantes (UPE) às atividades, seguindo até a redemocratização do país.

Neste primeiro período, as estudantes adentravam as universidades ainda sendo a minoria neste espaço ${ }^{3}$; desta forma, as militantes que ali se apresentam seguem a lógica da militância masculina já imposta pela formalidade do movimento estudantil.

\footnotetext{
${ }^{3}$ Em 1966, as mulheres ocupavam 31\% das vagas universitárias (BARROSO; MELLO, 1975). 
Neste contexto, não há espaço para o debate das questões femininas, poucas são as mulheres fichadas pela DOPS, e quando alguma é vista militando publicamente causa estranheza àqueles que presenciam.

Um exemplo é a reportagem do jornal Gaz̧eta do Povo, de 1968, cuja matéria trazia informações sobre a vigilância da DOPS em relação aos estudantes e, tendo este órgão percebido a formação de um comício-relâmpago, “[...] efetuou a prisão de três estudantes, inclusive uma môça $[\mathrm{sic}]^{4 "}$. Percebe-se o tom de surpresa utilizado na matéria ao se referir à mulher militante envolvida na ação, tendo sua presença notada com destaque. Com os temas sobre moralidade e conservadorismo sendo favorecidos pelo contexto autoritário, a militância feminina não era vista como algo possível. De acordo com Ana Maria Colling (2004), essas mulheres foram vistas pela repressão de forma negativa a partir de dois vieses: o primeiro por se mostrarem opositoras ao regime e o segundo por transgredirem o padrão de feminino que indicava seu lugar na sociedade.

Para Colling (2015, p. 378), a mulher idealizada pela ditadura deveria se colocar em seu lugar, "[...] no santuário do lar, cuidando do marido e dos filhos". Ainda para a autora, por este motivo, a militante era considerada uma "desviante" pela política repressiva, tendo a sua postura política desmerecida e sendo tratada como promíscua.

A repressão política buscou fomentar a inferiorização das mulheres e sobre suas ações aplicavam uma forma de censura moral. Assim, o aparato repressivo

[...] utilizou-se da discriminação de gênero para reforçar os estereótipos femininos de submissão e dependência emocional, afetiva e política. O tempo todo, a repressão política procurou coisificar e explorar "a condição de mulheres" para desmoralizar a militância de esquerda e reforçar as ideias mais retrógradas (TELES, 2015, p. 1002).

Essa questão da moral perseguia as mulheres militantes, pois, para a sociedade em geral, a mulher e política não era uma combinação aceitável, visto que, para uma boa mulher, mãe ou esposa, havia o ideal de não interferir em assuntos políticos. Desta maneira, quando as militantes eram vistas publicamente na seara política, logo recaíam sobre elas a censura moral, seja advinda dos agentes da polícia

\footnotetext{
${ }^{4}$ Gazeta do Povo, 1968. In: Arquivo Público do Paraná, DOPS-PR, Pasta Temática União Paranaense dos Estudantes - UPE, n. 2327, topografia 264. 
política, do governo autoritário, ou até dos próprios estudantes que compactuavam com os ideais da ditadura.

Sobre este fato, destacamos um relatório produzido por estudantes que participavam de um movimento denominado Movimento Universitário Autêntico (MAU), cujo pensamento político ia ao encontro do discurso ditatorial e objetivava vigiar os estudantes para revelar os comunistas presentes nas universidades. Tendo este grupo participado do XXX Congresso da UNE, juntamente com outras entidades estudantis, inclusive a UPE, em 1968, na cidade de Ibiúna-SP, decidiram redigir um manifesto relatando a "verdade" sobre o referido evento.

No documento, podemos observar que os estudantes do MAU “denunciam” que as meninas e meninos participantes dividiam o mesmo espaço para dormir, o que para eles significava que estas moças estavam perdidas em um antro de promiscuidade. Em outra passagem do mesmo documento chamam a atenção para uma militante da UPE, a qual chamam de "Miss Universitária Paranaense", pois sua imagem estaria envolvida em uma concorrência entre os demais estudantes, que visavam descobrir com qual deles ela dormiria durante a última noite do Congresso. Por fim, após a polícia invadir o local e prender alguns dos envolvidos com a organização do evento, estes estudantes do MAU destacam que a polícia política recolheu várias caixas de anticoncepcionais com as garotas estudantes 5 .

Percebe-se que na escrita do documento há um apelo para relacionar a presença das mulheres estudantes no Congresso às questões morais, denotando que a participação das mesmas no evento não passava de uma afronta à moral. Para Colling (1997, p. 41): "O governo militar sempre fez questão de aliar as questões morais [às políticas], principalmente com quem lhe fazia oposição”. Esta articulação inviabiliza assim as convicções políticas dessas militantes estudantis, rotulando-as a partir da moral, ao passo que ignora seu engajamento político.

Ainda no manifesto do MAU, a liberdade sexual das meninas é vista pejorativamente, o que não é colocado ao escreverem sobre os estudantes masculinos. Ressalta-se também que a menção às pílulas anticoncepcionais é utilizada de argumento para provar que as garotas que ali se encontravam eram

\footnotetext{
${ }^{5}$ Manifesto do MAU, 1968. In: Arquivo Público do Paraná, DOPS-PR, Pasta Temática União Nacional dos Estudantes - UNE (XXX゚ Congresso - Ibiúna) n. 2314, topografia 260. 
promíscuas e buscavam apenas sexo. Este argumento encontrava ressonância nos discursos produzidos pelo autoritarismo, pois, como a política não se relacionaria à identidade de gênero feminino, estas militantes eram consideradas desviantes a partir de determinadas características morais.

É também neste período que verificamos que, apesar de existir alguns registros de mulheres militando nas ruas com o movimento estudantil, quase não se tem a presença delas na composição das chapas da diretoria da UPE. Ao analisar a composição das chapas a partir do golpe até o ano em que a entidade teve suas atividades suspensas, percebemos que o número de mulheres era quase inexistente.

Quadro 1 - Mulheres na composição das chapas de diretoria da UPE.

\begin{tabular}{|l|c|}
\hline Gestão & $\begin{array}{l}\text { Total de mulheres } \\
\text { integrantes das chapas }\end{array}$ \\
\hline $1965-1966$ & 01 \\
\hline $1966-1967$ & 00 \\
\hline $1967-1968$ & 01 \\
\hline $1968-1969$ & 00 \\
\hline
\end{tabular}

Fonte: Pasta Temática União Paranaense dos Estudantes — UPE (1965-1969).

Observa-se na chapa composta para a diretoria de $1965 / 1966^{6}$, a qual inclusive era do campo do pensamento de direita e apoiava o governo militar, a presença da estudante Maria Lúcia, do curso de Educação Física. É interessante observar que a chapa "Reestrutura", de 1966/19677, vencedora do pleito, não possuía a participação de nenhuma mulher, e o mesmo aconteceu com sua concorrente, a chapa "Liberdade", que fora vencida nas urnas. A composição da 1967/1968 trouxe a estudante e militante ativa Palmira na função de coordenação da assistência estudantil. Por fim, a última chapa ativa antes de a UPE ser posta na ilegalidade, vencedora do pleito de 1968/1969, também não contou com nenhum nome feminino para sua diretoria ${ }^{8}$.

Além de esbarrar em um número inferior de mulheres no ensino superior, estes dados também estão diretamente ligados à figura de militante que era

\footnotetext{
${ }^{6}$ Concorrência à diretoria da UPE, 1965. In: Arquivo Público do Paraná, DOPS-PR, Pasta Temática União Paranaense dos Estudantes, n. 2325, topografia 263.

${ }^{7}$ Concorrência à diretoria da UPE, 1965. In: Arquivo Público do Paraná, DOPS-PR, Pasta Temática União Paranaense dos Estudantes — UPE, n. 2327, topografia 264.

${ }^{8}$ Idem.
} 
idealizada na época. De acordo com Santos (2011), a militância política é exercida por meio de um padrão essencialmente masculino. $\mathrm{O}$ arquétipo então é construído com a associação de características historicamente relacionadas aos homens para formar o militante, assim sendo, esse padrão é reproduzido nos espaços públicos e políticos, o que contribui para excluir, discriminar e oprimir a participação do gênero feminino nestes espaços.

Desta forma, a militância exigiria posturas e comportamentos característicos do sexo masculino, fator que contribuiria para manter o gênero feminino fora do espaço político formal.

O modelo masculino de militância política valoriza, assim, atributos de agressividade, competição, a fala em público, a disponibilidade de tempo. São valores que se confrontam com a identidade feminina historicamente construída que embora tenha passado por mudanças significativas na contemporaneidade, ainda se pauta em discursos que atribuem às mulheres um papel primordial na família e na reprodução, onde a educação e a socialização acabam por valorizar o seu confinamento e/ou maior identificação com o espaço privado e com arquétipos vinculados ao afeto, ao cuidado, às relações interpessoais (SOUSA; BEZERRA, 2006, p. 200).

Para muitas mulheres da época, estar em solo universitário já era um grande desafio frente às cobranças que a sociedade exigia daquelas que por muitos anos estiveram voltadas a aprender a ser uma exemplar senhora do lar, tendo em vista que, nas décadas anteriores, principalmente na era Vargas, houve inúmeras tentativas de direcionar as funções femininas exclusivamente para o lar. Expressão desta diferenciação de gênero, e como asseveram Schwartzman, Bomeny e Costa (2000), o ensino secundário inclusive trazia a disciplina de "ensino doméstico" para as mulheres, como o que foi sugerido no Plano Nacional de Educação de 1937. Na mesma direção, o "Estatuto da Família", elaborado em 1939, descrevia que a educação das mulheres deveria ser voltada para o casamento, para a maternidade, e que a elas coubesse a administração da casa.

Apesar de muitos avanços e conquistas de direitos que elas obtiveram até a década de 1960, é importante destacar que o Golpe civil-militar de 1964 se consolidou também a partir de um discurso moralista: "a retórica moralidade pública e dos bons costumes foi central na construção da estrutura ideológica que deu sustentação à ditadura de 1964” (QUINALHA, 2017, p. 25-26). 
Nesta perspectiva, o ser mulher e militante desviava-se completamente do ideal feminino propagado pelo Estado autoritário, que foi constituído sob a égide da família, do cristianismo e da moralidade, principalmente a partir das marchas femininas realizadas a favor do golpe.

[...] o estoque tradicional de imagens femininas e toda a gama de "valores morais, cristãos e familiares" que serviram de base para a mobilização de mulheres da direita contra Goulart não foram abandonadas pelos novos governantes militares e, de fato, tornaram-se as bases para a ideologia de gênero do novo regime autoritário (ALVAREZ, 1990, p. 6, apud NOREK, 2020, p. 30).

De acordo com Colling (1997, p. 111), a militante de esquerda, contrapondo-se a esta figura de mulher de família, "[...] é um desvio de mulher, vive na promiscuidade e não merece respeito. Se não está na política à procura de homens é porque é homossexual".

Assim, inseridas no ME enquanto militantes, elas também encontraram um espaço com barreiras a serem superadas. Práticas e valores impostos à vida pública, a masculinidade da política, contribuíram para manter as mulheres longe dos espaços formais onde a política acontecia. Para Michelle Perrot (2019, p. 184), “a ideia de que a política não é assunto das mulheres, que aí elas não estão em seu lugar, permanece enraizada, até recentemente, nas opiniões dos dois sexos".

Para Gianordoli-Nascimento et al. (2015) os/as estudantes que saíram às ruas em 1968 para questionar e lutar contra a ditadura e o sistema capitalista participaram de uma revolução dos costumes, “[...] de tal modo que, a participação de mulheres significava um rompimento com os códigos da época, entre eles os referenciais burgueses ligados à conjugalidade e à socialização feminina” (p. 112).

Porém, em 1969, com o fechamento da UPE, entidade máxima de representação estudantil no Paraná, os estudantes tiveram que recuar. Mesmo se organizando na clandestinidade, o aparato repressivo tratou de vigiar e repreender todas as ações que se formavam contra o governo. Os agentes da DOPS mantiveram-se vigilantes, produzindo documentos e registros sobre as ações de todos os estudantes os quais consideravam ter conexão com a militância política.

Este intervalo temporal leva a discutir a segunda fase da militância estudantil feminina durante o regime, mencionada anteriormente. A UPE ficou na ilegalidade 
por onze anos. Durante esse período os estudantes buscaram se articular politicamente nos Diretórios Centrais dos Estudantes (DCEs) das universidades. Em 1980, inicia-se uma pressão dos estudantes para a reestruturação da UPE, liderada, principalmente, por três mulheres.

As mudanças ocorridas com a juventude estudantil a partir do ano de 1968, no Brasil e no mundo, fizeram com que a categoria participasse de uma revolução cultural. Para Mesquita (2001), os estudos de Foucault e outros teóricos contribuem para uma discussão conceitual acerca da produção cultural oriunda da juventude neste período. E será a partir desta nova cultura que o movimento estudantil irá integrar em sua pauta discussões não apenas sobre classe social, mas também as questões de raça e gênero.

Além do mais, no que concerne às mudanças em relação à condição feminina, "a militância das mulheres promoveu uma revolução dos costumes, das formas de participação política, e dos modelos de casamento, virgindade e afetividade [...]" (GIANORDOLI-NASCIMENTO et al., 2015, p. 128). Essas mudanças podem ser vistas diretamente no interior do movimento estudantil após os anos 1980.

Após a volta da UPE ao cenário político-estudantil, as universitárias passaram a compor efetivamente esta entidade. As mulheres conquistaram o cenário político com sua militância; a presença delas nas universidades também aumentou, o que contribuiu para outras estudantes adentrarem no movimento.

Desta maneira, destacamos que a primeira eleição para a diretoria da UPE pós-retorno aconteceu em 1981 e foi composta pelas chapas "Mãos à obra" e "Pés no chão". Ambos os grupos já contavam com uma representação numérica significativa de mulheres em suas composições, tendo a chapa "Mãos à obra" sido formada por quatro estudantes homens e quatro mulheres. Por sua vez, uma destas estudantes era membro da UPE de antes de seu fechamento e continuou a participar assiduamente de eventos, greves e manifestações, chamando a atenção dos agentes da DOPS por ser uma militante ativa do movimento estudantil9.

\footnotetext{
${ }^{9}$ Chapas que concorreram à diretoria da UPE, em sua reabertura, 1981. In: Arquivo Público do Paraná, DOPS-PR, Pasta Temática União Paranaense dos Estudantes, n. 2326, topografia 263. 
Em relação à UNE, em 1982, tem-se a primeira presidenta eleita para dirigir a entidade, a estudante Clara Maria Araújo, do curso de Ciências Sociais da Universidade Federal da Bahia — UFBA, que se elegeu em um Congresso da UNE, sendo a $34^{\circ}$ presidente da instituição.

Percebe-se então que o movimento estudantil se abre para novas militantes, o que ocorre por dois processos: primeiro, que o número de matrículas nas universidades de mulheres nos anos 1980 era superior ao de 1964. Segundo, que a luta iniciada por estudantes na década de 1960, a crescente presença feminina na militância, as mudanças ocasionadas pelo ano da mulher em 1975 e o histórico do feminismo no Brasil permitiram que mais mulheres se agremiassem e se filiassem em entidades de representação política e sindical, que no caso das universitárias foi o movimento estudantil.

Outra modificação importante no ME partiu de uma mudança em sua estrutura organizacional. A partir da retomada das atividades nos anos 1980, o movimento instituiu o Departamento Feminino, divisão esta que era comandada por uma mulher e objetivava compreender "[...] até que ponto vai a discriminação da mulher nas atividades do ensino na Universidade"10.

Podemos ainda entender a necessidade da criação deste Departamento para as estudantes, a partir da entrevista da dirigente desta seção ao jornal Gaz̧eta do Povo (1981):

[...] há professores de determinadas áreas que excluem as mulheres alegando razões quase irracionais, como o fato de "urinarem" muito. Houve uma excursão dentro da Universidade do Paraná, onde professores não permitiram participação das alunas. Essa discriminação será combatida ${ }^{11}$.

Observa-se que a militância feminina passou a agregar as questões femininas, além das lutas gerais. A condição da mulher na universidade passou a ser questionada dentro do movimento estudantil, o que contribuiu, de certa forma, para a luta das mulheres na sociedade, pois estas estudantes conscientizavam outras sobre questões ligadas à sua categoria.

\footnotetext{
10 Idem.

11 Jornal Gazeta do Povo, 1981. In: Arquivo Público do Paraná, DOPS-PR, Pasta Temática União Paranaense dos Estudantes, n. 2326, topografia 263.
} 
A partir dos anos 1980 a militância feminina tem uma ascensão notável. Nos documentos da DOPS, nas Pastas Individuais das mulheres fichadas, há um maior volume de registros de mulheres estudantes atuando em palestras, manifestações, passeatas, trabalhos de bairro, datadas deste período. As mulheres já fichadas pela DOPS eram vigiadas e suas atividades militantes, consideradas suspeitas, eram merecedoras de registros detalhados por parte dos agentes.

A partir da análise destes registros, percebe-se que as mulheres estiveram engajadas em pautas que versavam sobre a mulher na sociedade, sobre o meio ambiente, sobre os trabalhadores e desempregados, sobre assuntos estudantis, e também lutando por eleições livres. As atividades eram principalmente organizadas por Debates, Encontros, Reuniões e Palestras, nas quais muitas vezes havia críticas ao governo.

A título de ilustração, há o registro de três estudantes que passaram a integrar a Frente Democrática da Mulher Londrinense, movimento que os agentes descrevem como tendo o objetivo de "[...] colocar a mulher dentro do contexto social, com uma participação de forma mais atuante" ${ }^{12}$. Ainda outras duas estudantes tiveram acrescidas às suas fichas a participação em encontros sobre o dia da mulher. Por sua vez, as pautas levantadas nesses encontros eram consideradas ações subversivas, o que levava ao registro de informações das estudantes envolvidas.

Marcelo Ridenti (1990) em seu trabalho de análise sobre os processos realizados pelo regime militar contra mulheres que possuíam ligações com as organizações de esquerda destaca que "a esmagadora maioria das denunciadas das esquerdas compunha-se de estudantes" (p. 115). A entrada na universidade foi a porta de acesso para a formação política e o movimento estudantil, o espaço para a formação da militante.

Neste âmbito, a categoria de gênero nos ajuda a compreender as diferenças estabelecidas na formação da militante num movimento que se engendra numa lógica estrutural da sociedade, marcada pelas diferenças entre os gêneros. Neste sentido, foi possível compreender que, na primeira fase do movimento estudantil paranaense analisada, as mulheres ficam excluídas da composição das chapas da

\footnotetext{
12 Pasta Individual n. 3210 topografia 464. Arquivo Público do Paraná, DOPS-PR. 
diretoria do movimento. Por conseguinte, há uma exclusão da figura feminina da liderança do movimento.

Como indicam Sousa e Bezerra (2006), dentro do movimento estudantil a fala em público, a divisão das tarefas, a linguagem utilizada e os comportamentos são masculinizados, propiciando que as lideranças políticas sejam "naturalmente" direcionadas para os participantes masculinos.

Já por parte da repressão política há uma tentativa de minimizar a militância feminina, desqualificando a sua luta, discurso também utilizado por alguns grupos de estudantes de direita. Há uma diferença no tratamento entre os gêneros, em que as mulheres não são vistas como militantes, assim como os estudantes masculinos o são, mas como apêndices dos homens que ali estão.

Na segunda fase da UPE há uma maior participação das mulheres, tanto nos cargos de diretoria quanto nas manifestações políticas. As estudantes continuam com a pauta de discussões direcionadas às causas sociais, porém, percebem-se os temas feministas também presentes. Fato este que modifica a estrutura no interior do próprio movimento estudantil, estabelecendo um espaço para estas novas pautas e cargos direcionados para a discussão sobre as mulheres, como a criação do Departamento Feminino.

Apesar das barreiras sociais encontradas por conta de seu gênero, as mulheres se constituíram na militância e no final dos anos de chumbo já haviam conquistado espaço, tanto na luta pela redemocratização do país quanto no debate das questões femininas.

Essa trajetória contou com a militância de muitas mulheres que sofreram as sanções do aparato repressivo ao tomar para si novas atuações, mas que também abriram espaço para outras práticas políticas.

\section{As militantes universitárias na União Paranaense dos Estudantes}

A educação das mulheres por décadas esteve relacionada, de certa forma, com o destino do lar, o cuidado dos filhos. Mesmo ao ingressar no ensino superior, 
as primeiras oportunidades que se abriram para elas foram os cursos adequados com a condição imposta e naturalizada a seu gênero.

A educação política esteve reservada aos homens, como se a política e o universo masculino fossem intrínsecos um ao outro. Essa situação é evidenciada ainda mais durante a ditadura, cuja alta esfera política era destinada apenas aos homens e brancos. A exclusão das mulheres do cenário político também é um exercício de poder que reforça as estruturas de hierarquia do gênero no autoritarismo. Por sua vez, quando se relacionam estas amarras postas às mulheres com a questão racial, temos ainda mais imbricadas as possibilidades de participação política e acesso ao ensino superior pelas mulheres negras - daí não podermos falar de feminismo no singular.

Nesse sentido, o período da ditadura militar reforçou o conservadorismo e as divisões sociais e raciais já presentes na sociedade brasileira, e munido de um aparato censório e repressivo buscou barrar qualquer mudança que fugisse a essa linha conservadora. Esse contexto exigiu da juventude uma atitude de protagonismo, o que a levou às ruas, aos gritos de ordem e ao protesto. Joana Maria Pedro (2005, p. 170) caracteriza que “nos anos setenta a 'missão’ era de luta contra a ditadura e por um mundo sem desigualdade — o qual seria conquistado através da manifestação em passeatas, palavras de ordem, panfletagem, grupos de consciência, atuação em bairros e associações”. E foi partindo desse modelo de militância que muitas estudantes adentraram este espaço de luta.

Para se mapear a militância feminina contra a ditadura, como afirma Conradi (2020), é necessário construir esse percurso a partir da atuação destas militantes, dando visibilidade a estes protagonismos feminismos, ao mesmo tempo em que se identifica a formação destas mulheres enquanto sujeitos políticos. Desta maneira, destacamos aqui as militâncias de duas estudantes da UPE, Judite e Palmira.

A militância de Judite foi muita ativa e data de fins da década de 1960. Em sua Pasta Individual encontramos vários registros feitos pela polícia política sobre a militante, como também cópia de documentos "subversivos" encontrados em posse da mesma, como o Manifesto dos Estudantes de $1968^{13}$. A militância de Judite

\footnotetext{
${ }^{13}$ Pasta Individual, n. 2246, topografia 4603. Arquivo Público do Paraná, DOPS-PR. 
acontecia nas ruas, junto com outros colegas, quando buscava conscientizar a categoria estudantil sobre as atitudes repressivas que o governo vinha exercendo.

De acordo com Sanfelice (1986), os estudantes saíam às ruas protestando contra as medidas educacionais tomadas pelo governo, como a Lei Suplicy e os acordos MEC-USAID. A UNE buscava conscientizar os estudantes sobre a necessidade de se derrubar a ditadura, e assim buscavam consolidar suas lutas juntamente com o restante do povo oprimido por esta forma de governo. Em resposta, a repressão perseguiu violentamente os estudantes, sob a alegação de infiltração comunista dentro do movimento.

Durante a participação no Congresso da UNE que aconteceu na Chácara do Alemão, em Curitiba, no dia 17 de dezembro de 1968, apenas quatro dias depois da assinatura do fatídico Ato Institucional n 5 (AI-5), a militante foi detida pela polícia política, junto com outros colegas, e “[...] cumpriu pena de detenção na Prisão Provisória de Curitiba ${ }^{14}$, por infração à Lei de Segurança Nacional"15. Judite foi julgada junto com outra colega e mais 13 estudantes e cumpriu pena de um ano no Presídio do Ahú.

A militância não foi uma escolha aleatória, de acordo com seu testemunho dado ao "Depoimentos Para a História"16. Judite declarou que teve contato com a política em sua adolescência, porém foi uma aproximação superficial, já que seu pai, antes do golpe, foi cabo eleitoral do Partido Trabalhista Brasileiro, e em 1966 já tinha participação no movimento estudantil secundarista.

A então professora aposentada relatou que foi a partir de 1967, depois de entrar para o curso de História na cidade de Curitiba, que de fato iniciou sua militância no ME universitário, cujo principal debate girava em torno dos acordos

\footnotetext{
${ }^{14}$ Para os/as presos/as políticos/as detidos na região de Curitiba e proximidades, "[...] a Prisão Provisória de Curitiba (Ahú) era o principal local. Outras alternativas eram o Quartel General da Polícia Militar na praça Rui Barbosa, o Dops na rua João Negrão, o Hospital Militar no alto da rua Vicente Machado, a antiga sede da Polícia Federal na rua Carlos Cavalcanti e o Comando da $5^{\circ}$ Região Militar, antigo CPOR (Centro de Preparação de Oficiais da Reserva) na praça Osvaldo Cruz, onde atualmente é o Shopping Curitiba. Outro endereço era o Presídio Feminino de Piraquara, na região metropolitana de Curitiba" (CALCIOLARI, 2004, p. 118).

15 Pasta Individual, n. 2246, topografia 4603. Arquivo Público do Paraná, DOPS-PR.

${ }^{16} \mathrm{O}$ depoimento da militante Judite encontra-se no link: http://bit.ly/2sql1JH, em um compilado denominado Depoimentos para a História: A resistência à ditadura Militar, organizado por DHPAZ — Direitos Humanos Para a Paz e Tortura Nunca Mais Paraná.
} 
MEC-USAID. Neste período experienciou muitas participações em assembleias, manifestações e passeatas.

Apesar de nos registros da DOPS-PR constar apenas a prisão da militante durante a participação do Congresso da UNE em Curitiba, ela revela em seu depoimento que fora presa uma vez por participar de uma passeata e outra por fazer panfletagem, ambas antes de 1968. Após cumprir sua pena no Presídio do Ahú, a estudante retomou seus estudos e prosseguiu ativa na militância, dedicando-se a outros movimentos sociais. Ainda durante o regime militar saiu em defesa dos docentes e participou da Campanha pela Anistia no fim dos anos 1970 (OLIVEIRA; SAHD; CALCIOLARI, 2014).

A integração das militantes no movimento estudantil tornou rotineira sua participação em passeatas, manifestações e panfletagens. Contudo, para o governo autoritário, essas ações sinalizavam perigosamente contra a ideologia do regime, o que impulsionava a polícia política a tratar esses atos em defesa da democracia como perigosos e criminosos, levando militantes à prisão.

A universidade durante o período da ditadura militar passou a ser espaço de debates sobre a situação em que o país se encontrava; consequentemente, a repressão imposta pelos militares no governo recaiu sobre essa instituição, levando o temor da repressão sobre todas as práticas ou ideias consideradas subversivas. "A mera acusação de que uma pessoa, um programa educativo ou um livro tivesse inspiração 'comunista' era suficiente para demissão, suspensão ou apreensão" (CUNHA; GÓES, 2002, p. 36). Desta forma, a universidade era constantemente vigiada, com o objetivo de barrar a discussão intelectual sobre a realidade brasileira e prender possíveis subversivos. Para tanto, a ditadura inclusive contou com os serviços de vigilância e informação da Assessoria Especial de Segurança e Informações (AESI), presente no interior de algumas universidades, como foi o caso, por exemplo, da Universidade Estadual de Londrina e da Universidade Federal do Paraná.

Homens e mulheres militantes estudantis não escaparam à dura repressão, que envolvia perseguição, prisão, interrogatórios e até mesmo tortura. Nesse período, a tortura esteve à espreita nos interrogatórios e serviu de instrumento para a obtenção de informações e disseminação do medo por parte dos agentes da repressão. 
Os interrogatórios buscavam desvendar o militante, intimidando-o, e por sua vez havia uma preocupação em montar uma rede de informações, tentando encontrar uma relação entre o interrogado e outros militantes. Assim também aconteceu com a estudante e militante Palmira quando foi levada de sua casa até a DOPS, em 1970.

O documento intitulado Auto de Declaração contém o depoimento de Palmira, que foi interrogada na presença do temido delegado Ozias Algauer. Neste documento, ela informa sob interrogatório que é estudante de Economia e fornece informações sobre onde vive. Os agentes a questionam então sobre um militante, ao qual ela responde ter conhecido em 1968 e namorado em 1969, porém, devido à prisão de Palmira no presídio Tiradentes, os dois haviam terminado ${ }^{17}$.

Buscando saber sobre outros militantes, os agentes a indagam sobre mais dois estudantes, porém, Palmira responde que os conheceu à época que esteve na vice-presidência da UPE, quando se encarregava da função dos Assuntos Educacionais e Culturais, e não lhes fornece nenhuma informação a mais.

Palmira é uma militante que possui vários registros na polícia política por sua atuação marcante na militância, principalmente durante o período mais rigoroso do regime militar. Durante o $30^{\circ}$ Congresso da UNE em Ibiúna, mais exatamente no dia 12 de outubro de 1968, cerca de 200 mulheres foram presas. Entre elas, estava Palmira, junto com outros/as estudantes, dentre eles/as, outras quatro mulheres do Paraná. No documento intitulado Serviço de Informação, o qual foi assinado pelo delegado da DOPS, Ozias Algauer, foi registrada a prisão de Palmira, que inicialmente ficou detida no presídio Tiradentes, tendo depois continuado presa na “[...] Prisão Provisória de Curitiba, no bairro Ahú de Baixo, à disposição da $2^{\text {a }}$ Auditoria da Justiça Militar".

A militância de Palmira no ME universitário foi muito ativa. A mesma chegou a ser vice-presidente da UPE e presidente da Casa da Estudante Universitária. Também atuou no Conselho Fiscal do Teatro do Estudante Universitário, esteve também à frente de projetos da luta universitária, como na crise do Restaurante Universitário e nos protestos pelo paradigmático e comovente

\footnotetext{
${ }^{17}$ Pasta Individual, n. 3042 topografia 453. Arquivo Público do Paraná, DOPS-PR. 
assassinato praticado por um policial militar contra o estudante Edson Luís de Lima Souto (1950-68), no Restaurante Calabouço, no Rio de Janeiro.

A militância estudantil também abriu espaço para esta estudante em outros grupos, como o Movimento Contra a Ditadura, que ela chegou a presidir ${ }^{18}$ e que funcionava como órgão de propaganda da Organização Revolucionária Marxista Política Operária (POLOP). Estando sempre na "linha de frente" da resistência às ações do autoritarismo, esta estudante foi vigiada e perseguida pela DOPS por ser considerada subversiva. Por um longo período, entre 1967 a 1970, há escritos sobre suas ações, porém, a partir dos anos 1970 cessam seus registros na polícia política do Paraná.

A militância no ME permitiu que outras práticas e formas de atuação emergissem dentro do movimento político-estudantil. Muitas mulheres assumiram posições de liderança, tanto frente às manifestações como na coordenação dos projetos da UPE, enquanto outras estiveram atuantes como ouvintes, produzindo cartazes, distribuindo panfletos pela rua, conscientizando outros estudantes. Em todas estas configurações a mulher pode se constituir como ser político no espaço da universidade e para além dele.

As fontes investigadas permitem delinear a participação político/educacional destas estudantes inseridas num contexto de censura e repressão. Neste palco, cada estudante assumiu diferentes posturas frente à militância, contribuindo para o desmonte dos estereótipos construídos acerca da figura feminina e reforçados pelo conservadorismo presente na ditadura.

Ao trabalhar a participação feminina no movimento estudantil a partir da categoria de gênero, observamos que as mulheres se constituíram como militantes em um ambiente politicamente estruturado a partir de um conceito de militância masculina. Dessa forma, a militância feminina teve que ser construída rompendo com estereótipos sociais existentes acerca do ser feminino, desafiando os papéis designados a elas no espaço político.

Principalmente na primeira fase de atuação da UPE, as estudantes enfrentaram maior repressão, sendo algumas levadas à prisão. A militância no movimento estudantil permitiu que muitas estudantes também se engajassem em

\footnotetext{
18 Idem.
} 
outros movimentos, sendo perseguidas e vigiadas pelo sistema repressivo, que dentro de suas práticas misóginas “[...] não deixaram de 'reconhecer' a tenacidade e a capacidade de luta das mulheres para se empenhar na militância de esquerda e as torturaram igualmente como os demais e, sem ignorar suas diferenças, usaram delas para praticar as mais diversas e cruéis atrocidades" (TELES, 2015, p. 1002).

Neste âmbito, estas mulheres tiveram que enfatizar um combate não apenas contra o Estado autoritário, mas também contra a sociedade conservadora que não permitia sua libertação, enfrentando os desafios de ser a minoria nas universidades, o rigor e desaprovação oriundos de seus familiares, bem como o descrédito de seu papel político por parte dos agentes do Estado. As resistências femininas estabelecidas neste contexto tiveram uma amplitude social que não podemos nos descurar.

\section{Considerações finais}

Apesar de muitas figuras femininas conduzirem no Brasil um caminho em prol da educação para as mulheres já no século XIX, a inserção delas no sistema de ensino foi lenta e gradual, pois havia um controle social sobre a socialização de seu gênero. A privação das mulheres ao sistema de ensino em todos seus níveis é resultado das imbricadas relações de poder que passam pelas questões de gênero na nossa sociedade.

Inseridas na universidade, as mulheres se constituíram como seres políticos em uma entidade de cunho político/educacional, o movimento estudantil. Por sua vez, este era composto por formalidades próprias da política formal e exigia de seus militantes determinados comportamentos. Nesse sentido, a participação feminina no interior deste grupo levou as mulheres a se distanciarem do privado e a ocupar o espaço público, marcado historicamente pela presença masculina.

Com a inserção das mulheres no espaço público no âmbito político, em um contexto repressivo, cuja onda conservadora opunha-se às liberdades democráticas, essas militantes configuraram novas resistências, atuando na arena pública; perseguidas pelos agentes devido a suas atitudes "subversivas", buscaram meios para gerir seus trabalhos de luta pela democracia. 
Desta maneira, no Brasil, as mulheres foram tomando este espaço político formal, e o movimento estudantil contribuiu para muitas delas ingressarem neste setor até então essencialmente masculinizado. Durante o período mais intenso da repressão do regime, seus nomes foram aparecendo, suas faces foram sendo reconhecidas nas ruas, elas tornaram-se militantes e um perigo para os agentes da repressão. Com responsabilidades que se sobrepunham às tarefas eminentemente masculinas, levaram em frente as mais diversas lutas na transição política, ainda que em meio a uma dupla jornada de trabalho, em casa e no trabalho, e ainda sendo vítimas da violência de gênero.

Muitas destas mulheres lutaram para recuperar seus filhos e filhas e companheiros das celas pútridas do poder ditatorial, para encontrar os corpos dos desaparecidos, para curar as feridas visíveis e invisíveis das prisões e das torturas que algumas delas sofreram, tiveram que sobreviver ao exílio, inclusive interno, organizaram os movimentos pela anistia e contra a carestia, tomaram a frente das direções de sindicatos docentes, organizaram associações de bairro e seguiram empunhando as bandeiras das feministas que as precederam. A luta e a história das mulheres educam.

\section{Referências}

BARROSO, C. L.; MELLO, G. N. O acesso da mulher ao ensino superior brasileiro. Cadernos de Pesquisa, n. 15, p. 47-77, 1975.

BRAGGIO, A. K.; FIUZA, A. F. Acervo da DOPS/PR: uma possibilidade de fonte diferenciada para a história da educação. Revista Tempo e Argumento, Florianópolis, v. 5, n. 10, p. $430-452,2013$.

CALCIOLARI, S. Ex-presos politicos e a memória social da tortura no Paraná (1964-1978). 2004, 211p. Dissertação (Mestrado em Sociologia) — Universidade Federal do Paraná, Curitiba, 2004.

COLLING, A. M. A resistência da mulher à ditadura militar no Brasil. Rio de Janeiro: Record; Rosa dos Tempos, 1997.

COLLING, A. M. As mulheres e a ditadura militar no Brasil. In: CONGRESSO LUSOAFRO-BRASILEIRO DE CIÊNCIAS SOCIAIS, 8., Coimbra, 2004. Anais... Coimbra: [s.n.], 2004.

COLLING, A. M. 50 Anos da ditadura no Brasil: Questões feministas e de gênero. OPSIS, Catalão, v. 15, n. 2, p. 370-383, dez. 2015. 
CONRADI, C.C.N. Gênero, Memória e ditadura: A militância política de Lídia Lucaski no Paraná. História: Questões \& Debates, Curitiba, v. 68, n. 01, p. 261-296, jan./jun. 2020.

CUNHA, L. A.; GÓES, M. (Org.). O golpe na educação. 11. ed. Rio de Janeiro: Jorge Zahar, 2002.

GIANORDOLI-NASCIMENTO, I. F. et al. Representações sociais de "ser mulher militante": As imbricações entre geração e gênero na trajetória de militância de mulheres durante a ditadura militar brasileira. Memorandum, v. 28, p. 110-131, abr. 2015.

MESQUITA, M. R. Juventude e movimento estudantil - O "velho" e o "novo" na militância. 2001. 189p. Dissertação (Mestrado em Ciência Política) - Universidade Federal de Santa Catarina, Florianópolis, 2001.

NOREK, A. Y. "Mulheres do Brasil" ou terroristas? As muitas representações da mulher durante a Ditadura Militar (1964-1985). Revista Em Perspectiva, v. 6, n. 1, p. 26-40, 2020.

OLIVEIRA, A. N. P. de, SAHD, F. B. \& CALCIOLARI, S. Depoimentos para a história: a resistência à ditadura militar no Paraná. Curitiba: DHPaz, 2014.

PEDRO, J. M. Feminismo e Gênero na universidade: Trajetórias e tensões da militância. História Unisinos, v. 9, n. 3, p. 170-176, set./dez. 2005.

PERROT, M. Minha História das Mulheres. 2. ed. São Paulo: Contexto, 2019.

QUINALHA, R. H. Contra a moral e os bons costumes: a política sexual da ditadura brasileira (1964-1988). 2017. 329f. Tese (Doutorado em Relações Internacionais) — Instituto de Relações Internacionais, Universidade de São Paulo, São Paulo, 2017.

RIDENTI, M. S. As mulheres na política brasileira: os anos de chumbo. Tempo Social, São Paulo, v. 2, n. 2, p. 113-128, 2º sem. 1990.

SANFELICE, J. L. Movimento Estudantil: A UNE na Resistência ao Golpe de 64. São Paulo: Cortez; Autores Associados, 1986.

SANTOS, M. F. T. dos. Mulheres no movimento estudantil: Representações, discursos e identidades. 2011. 92f. Dissertação (Mestrado em Ciências Sociais) — Universidade Federal de Juiz de Fora, Minas Gerais, 2011.

SCHWARTZMAN, S.; BOMENY, H. M. B.; COSTA, V. M. R. Tempos de Capanema. 2. ed. Rio de Janeiro: Fundação Getúlio Vargas; Editora Paz e Terra, 2000.

SOUSA, R.; BEZERRA, T. C. Juventude, movimento estudantil e gênero: problematizando o modelo masculino de militância. Revista O público e o privado, n. 8, p. 197 215, jul./dez. 2006.

TELES, M. A. A. Violações dos direitos humanos das mulheres na ditadura. Estudos Feministas, Florianópolis, v. 23, n. 3, p. 1001-1022, set./dez. 2015. 
WOLFF, C. S. O gênero da esquerda em tempos de ditadura. In: PEDRO, J. M.; WOLFF, C. S. Gêneros, feminismos e ditaduras no cone sul. Florianópolis: Ed. Mulheres, 2010.

RECEBIDO: $17 / 06 / 2020$

APROVADO: 10/04/2020

RECEIVED: 06/17/2020

APPROVED: 04/10/2020

RECIBIDO: $17 / 06 / 2020$

APROBADO: $10 / 04 / 2020$ 